Revista Científica do Instituto Agronomico, Campinas

\title{
ALTA DENSIDADE DE PLANTIO EM AMEIXEIRA (PRUNUS SALICINA LINDLEY) CV. CARMESIM (1)
}

Márto Ojima (2), Fernando A. Campo Dall'Orto (2), Seção de Fruticultura de Clima Temperado, ORLANDo RigitaNo, Diretor da Divisão de Horticultura, ARY De ARruda Veiga, Estação Experimental de Tietê, Antonio Fernando Caetano Tombolato (2), Seção de Fruticultura de Clima Temperado, José Carlos Sabino $\left({ }^{2}\right)$, e Sandra M. Capeline Egydio, Estação Experimental de Tietê, Instituto Agronômico

A cultura da ameixeira no planalto do Estado de São Paulo e em regiōes edafoclimáticas análogas, vem-se expandindo gradualmente nos últimos dez anos, em grande parte devido ao lançamento do cultivar Carmesim, selecionado pelo Instituto Agronômico em $1969{ }^{(3)}$. Existem, atualmente, no Estado, cerca de 300.000 ameixeiras desse cultivar, cujas características de adaptaçāo, produtividade, precocidade e qualidade dos frutos deram ensejo à expansão da cultura até em zonas consideradas apropriadas apenas para fruteiras tipicamente subtropicais.

Tendo em vista a alta capacidade de frutificação do 'Carme- sim' e a tendência à adoção, na fruticultura moderna, de plantios densos visando à obtenção de maior produtividade por área, efetuou-se o presente estudo, a fim de avaliar o comportamento desse cultivar quando submetido a espaçamentos mais reduzidos que os normalmente adotados.

Material e métodos: o experimento foi conduzido na Estação Experimental de Tietê, do Instituto Agronômico, situada a uma altitude de $525 \mathrm{~m}$ e apresentando os seguintes dados meteorológicos anuais, no período de janeiro de 1977 a dezembro de 1978: precipitação pluvial, $1.132 \mathrm{~mm}$; temperatura média, $22,0^{\circ} \mathrm{C}$, e umidade relativa do ar, $76,0 \%$

(1) Recebida para publicação a 28 de junho de 1979.

() Com bolsa de suplementação do CNPq.

(3) RIGITANO, O. \& OJIMA. M. Carmesim - nova ameixa para o Estado de São Paulo. Campinas, Instituto Agronômico, 1973. 20p. (Boletim, 205) 
O lote experimental foi instalado em terreno plano, em solo classificado como Podzólico Vermelho-amarelo Orto, variação Laras.

Foram utilizadas mudas do cultivar Carmesim enxertadas sobre o pessegueiro 'Okinawa', resistente a nematóides do gênero Meloidogyne $(4,5)$. Adotaram-se quatro espaçamentos de plantio: $5 \times 1 \mathrm{~m}, 5 \times 2 \mathrm{~m}, 5 \times 3 \mathrm{~m}$ e $5 \times$ $4 \mathrm{~m}$, em delineamento em blocos ao acaso com cinco repetições, representadas por cinco fileiras de plantas distanciadas de cinco metros, cada uma com quatro canteiros correspondentes às variações de espaçamento. Cada canteiro, tendo $12 \mathrm{~m}$ de comprimento e $60 \mathrm{~m}^{2}$ de área, separado por uma planta-bordadura, foi formado com doze, seis, quatro e três ameixeiras respectivamente, nos espaçamentos de $1,2,3$ e $4 \mathrm{~m}$ de distância entre as plantas.

A instalação do ensaio foi feita em agosto de 1976, plantando-se as mudas em covas com adubação fundamental, constituída de $20 \mathrm{~kg}$ de esterco de curral, $800 \mathrm{~g}$ de superfosfato simples, $100 \mathrm{~g}$ de cloreto de potássio e $500 \mathrm{~g}$ de calcário dolomítico, baseada em observações experimentais, da Seção de Fruticultura de Clima Temperado, para solos representativos das condições médias do Estado de São Paulo. Iniciado o desenvolvimento vegetativo, as plantas receberam, individual- mente, quatro aplicações, com intervalos mensais, de 50 a $80 \mathrm{~g}$ de sulfato de amônio, em cobertura. Nessa primeira fase, não se diferenciaram as quantidades de nutrientes aplicados por canteiro, dado objetivar-se um desenvolvimento inicial, mais homogêneo das plantas .

Em 1977, efetuou-se a seguinte adubação, por canteiro experimental, em cobertura: $1,5 \mathrm{~kg}$ de sulfato de amônio, $1,5 \mathrm{~kg}$ de superfosfato simples e $0,6 \mathrm{~kg}$ de cloreto de potássio; essas doses foram duplicadas no ano seguinte.

As ameixeiras foram conduzidas, o quanto possível, na sua formação natural. As podas consistiram na eliminação dos ramos mal distribuídos e excedentes, e desponta dos mais longos, de um terco do seu comprimento, durante o inverno, complementadas com desbrotas periódicas na vegetação.

Após as podas de inverno, efetuadas em julho, as plantas receberam irrigação por duas vezes, com intervalo de quinze dias; em seguida, fez-se o amanho do solo e cobertura morta ao redor das plantas com palha de trigo. Nas entrelinhas, o terreno foi mantido suficientemente limpo, por meio de três a quatro gradagens.

Como tratamento fitossanitário de inverno, fez-se, anualmente, uma pulverização das

(4) MENTEN, J. O.; LORDELlO, L. G.; CAMPO DALl'ORTO, F. A.; OIMA, M. \& RIGITANO, $O$. Resistência varietal do pessegueiro (Prunus persica Batsch) aos nematóides Meloidogyne incognita e $\dot{M}$. arenaria. In: REUNIÄO DE NEMATOLOGIA, 2., Piracicaba, 1976. Anals, Sociedade Brasileira de Nematologia, 1977. v.2. p.165-174.

(5) RIGITANO, O.: OJIMA, M. \& CAMPO DALl'ORTO, F. A. Comportamento de novas seleções de pêssegos introduzidas da Flórida. Campinas, Instituto Agronômico, 1975. 12p. (Circular, 46) 
plantas com . Dinitro-orto-cresol; os troncos foram pincelados com pasta sulfocálcica. Durante a vegetação, efetuaram-se pulverizações quinzenais com os fungicidas Mancozeb e enxofre molhável, o acaricida Clorobenzilato e os inseticidas Parathion metílico, Fenthion e Demeton S-methyl.

Em 1977, constataram-se as primeiras frutificações que, sendo ainda reduzidas e irregulares, não foram consideradas no presente trabalho. Em 1978, procedeu-se à colheita controlada em diversos repasses, no período de 25 de outubro a 18 de dezembro, anotando-se a produção em número e peso dos frutos, individualmente por planta.

Resultados e discussão: No quadro 1, são apresentados os dados de produção da ameixeira 'Carmesim', relativos a número e peso de frutos por canteiro, peso de um fruto, produção por planta e por área, em plantas de dois anos de idade, nos quatro espaça- mentos considerados, e correspondentes à safra de 1978.

Prescindiu-se de análise estatística, em face da evidência dos resultados experimentais obtidos. Constatou-se que o menor espaçamento - $5 \times 1 \mathrm{~m}$ - correspondente a uma densidade de plantio de 2.000 plantas por hectare propiciou produção de 15,5 toneladas de ameixas, cerca de três vezes maior que a do espaçamentto de menor densidade de plantas, isto é, de $5 \times 4 \mathrm{~m}-500$ plantas por hectare.

Verifica-se, por outro lado, que a produção individual no espaçamento de $5 \times 1 \mathrm{~m}$ foi de $7,7 \mathrm{~kg}$, ou seja, cerca de $30 \%$ menor que a dos demais tratamentos, respectivamente, $11,1,11,5$ e $10,5 \mathrm{~kg} /$ planta. Entretanto, essa produção menor foi compensada, no canteiro, pelo maior número de plantas, o que permitiu obter produções por área superiores em cerca de três, duas e uma vez e meia, respectivamente, às obtidas

QUADRO 1. - Produção média da ameixeira 'Carmesim', em Tietê (SP), no ano agrícola de 1978, em plantas de dois anos de idade, nos espaçamentos de $5 \times 1 \mathrm{~m}$, $5 \times 2 \mathrm{~m}, 5 \times 3 \mathrm{~m}$ e $5 \times 4 \mathrm{~m}$ : número e peso dos frutos por canteiro, peso de um fruto, e produção por planta e por área

\begin{tabular}{|c|c|c|c|c|c|}
\hline \multirow{2}{*}{ Espaçamento } & \multicolumn{4}{|c|}{ Produção } & \multirow{2}{*}{$\begin{array}{c}\text { Fruto } \\
\text { maduro }\end{array}$} \\
\hline & Por planta & Canteiro & $0 \mathrm{~m}^{3}$ & Hectare & \\
\hline $\mathrm{m}$ & $\mathbf{k g}$ & n. ${ }^{\circ}$ de frutos & $\mathbf{k g}$ & $\mathbf{k g}$ & g \\
\hline $5 \times 1$ & 7,7 & 3.402 & 92,9 & 15.483 & 27,3 \\
\hline $5 \times 2$ & 11,1 & 2.412 & 66,8 & 11.133 & 27,7 \\
\hline $5 \times 3$ & 11,5 & 1.580 & 45,9 & 7.650 & 29,1 \\
\hline $5 \times 4$ & 10,5 & 1.059 & 31,5 & 5.250 & 29,8 \\
\hline
\end{tabular}


nos espaçamentos de $5 \times 4,5 \times 3$ e $5 \times 2 \mathrm{~m}$ entre as plantas.

Sem mostrar diferenças marcantes, verificou-se, também, que quanto menor o espaçamento, menor foi o peso médio de uma ameixa madura, que variou de 29,8 a $27,3 \mathrm{~g}$.

As produções obtidas no presente ensaio podem ser consideradas auspiciosas, como aquela relatada por VORSTER \& STADLER $\left({ }^{6}\right)$, na África do Sul, com o cultivar Harry Pickstone, enxertado sobre a ameixeira ' $\mathrm{Ma}$ rianna', livre de vírus, em cultura conduzida em espaldeira, no espaçamento $4,6 \times 2,7 \mathrm{~m}$, correspondente a 800 plantas por hectare, a qual produziu, no segundo ano, $7 t$ por hectare. No experimento aqui realizado, os espaçamentos, de $5 \times 2$ e $5 \times 3 \mathrm{~m}$, correspondentes a 1.000 e 650 plantas por hectare, portanto bem próximos daquele adotado na África do Sul, proporcionaram respectivamente 11 e 7,5 toneladas de ameixas por hectare.

Os resultados aqui obtidos vêm ratificar a grande capacidade de frutificação que o cultivar Carmesim apresenta. Em pomares comerciais bem cuidados, em espaçamento ao redor de $6 \mathrm{x}$ $5 \mathrm{~m}$, têm-se constatado colheitas de 5 e $15 \mathrm{~kg}$ de ameixas nas plan- tas de um e dois anos de idade respectivamente, e de mais de $100 \mathrm{~kg}$ nas adultas. Sua alta produtividade, aliada à precocidade com que produz safras comerciais, viabilizam a adoção de espaçamentos mais compactos que os comumente empregados, permitindo significativo ganho no rendimento por área, nos primeiros anos do pomar.

Finalmente, é importante ressaltar que o espaçamento de 5 x 1m, não obstante tenha propiciado a maior produção por área, no segundo ano após a instalação do lote, já está mostrando o inconveniente da excessiva aglomeração entre plantas vizinhas, fato ainda não observado nos espaçamentos mais amplos. $\hat{E}$ de esperar, portanto, uma relativa diminuição das cargas nas plantas submetidas a espaçamentos reduzidos, à medida em que se intensificar a competição entre as mesmas, chegando-se à fase em que a produtividade deverá equilibrar-se com a dos tratamentos de menor densidade. A averiguação desse ponto de equilíbrio, da reação adaptativa ao excessivo adensamento, bem como do subsequiente desbaste das plantas, nos espaçamentos mais reduzidos, deverá constituir o prosseguimento deste trabalho.

\section{DENSE SPACING IN PLUM TREE (PRUNUS SALICINA} LINDLEY) CV. CARMESIM

\section{SUMMARY}

An experiment was carried out during 1976/78, at Tietê, SP, to study the behaviour of 125 plum trees, cv. Carmesim, under four planting distances: $5 \times 1 \mathrm{~m}, 5 \mathrm{x} 2 \mathrm{~m}$, $5 \times 3 \mathrm{~m}$ and $5 \times 4 \mathrm{~m}$, respectively.

(6) VORSTER, D. J. \& STADLER, J. D. A new approach to the cultivation of plums. Deciduous Fruit Grower. South Africa. 26(6):222-237, 1976. 
The yields obtained from the 1978 harvest in its second crop were 15.5, 11.1, 7.6 and 5.3 tons per hectare, corresponding to the planting density of 2000, 1000, 650 and 500 trees per hectare, respectively.

'Carmesim', has proven to be a very prolific early bearer of plum of excellent quality. 